\title{
Effect of ventilation on thermal comfort in campus hostel bedrooms after sunset
}

\author{
Shaharin Anwar Sulaiman, ${ }^{1, *}$, Ahmad Faridzuan Zakeria ${ }^{1}$, Muhammad Fahmi Ramely ${ }^{1}$, Mohamad Nazmi Zaidi \\ Moni $^{1}$ and Mohamad Firdaus Basrawi ${ }^{2}$ \\ ${ }^{I}$ Mechanical Engineering Department, Universiti Teknologi PETRONAS, 32610 Bandar Seri Iskandar, Perak, Malaysia \\ ${ }^{2}$ Faculty of Mechanical Engineering, Universiti Malaysia Pahang, 26600 Pekan, Pahang
}

\begin{abstract}
After sunset, the indoor of buildings would be relatively warmer as compared to that of the outdoor due to thermal was associated with the heat stored in the building structures and furniture. In tropical countries, doors and windows are usually shut after sunset in order to avoid mosquitoes. Thus, the condition of the indoor air is worsened as the hot air is trapped inside the bedroom and takes long time to be fully dissipated to the surrounding. This causes discomfort to the occupants as bedrooms where they are expecting to have a good rest to rejuvenate from hard day works. The objective of this study was to analyze the nature of air temperature profile in bedrooms of a hostel at night and the effect of ventilation systems in reducing the indoor air temperature. The study was conducted by measuring temperature of air in the bedrooms throughout a night. It was found that the exhaust fan gave the best results by reducing the air temperature by $1.5^{\circ} \mathrm{C}$ to $2.5^{\circ} \mathrm{C}$.
\end{abstract}

\section{Introduction}

During the day, buildings experience heat gains from several sources. The heat radiated from the sun during the day is absorbed and stored by equipment, furniture and structure of the building. After the sun is set, due to temperature different the stored heat is emitted to the surrounding causing the indoor temperature to increase and becomes relatively higher than that of the outdoor air ${ }^{1}$. This situation creates uncomfortable environment to the bedroom occupants during night time because the thermal comfort condition in the bedroom cannot be maintained. The concept of thermal comfort is closely related to thermal stress. People do not perform well under thermal stress. People's performance under thermal stress is about $11 \%$ lower than their performance at normal thermal conditions ${ }^{2}$. In this context, student's life should not be excluded. In university's residential buildings, the residents which are the students spend a lot of their time in the bedroom during night time as the building is designed with bedrooms only. Hence, most of student activities especially studying is done in the respective bedroom. The increase in temperature during night time in the bedroom space could affect the overall academic performance of the students if it is not solved properly. Besides that, prolonged heat can give consequences to the psychological aspect especially to those that have history in psychological problems. People that exposed to prolonged elevated temperature may behave differentially and aggressively in respond to the surrounding thermal ${ }^{3}$. Thus, it is very important to keep the bedroom environment in thermal comfort condition to avoid any commotion in student. Malaysia has hot and humid climate with temperatures ranging between $20^{\circ} \mathrm{C}$ and $32^{\circ} \mathrm{C}$ during daytime, and $21^{\circ} \mathrm{C}$ to $27^{\circ} \mathrm{C}$ during the night with relative humidity of around $75 \%{ }^{4}$. The occupants of houses are usually open their doors and windows for natural ventilation during daytime. Thus, the indoor air temperature is increased due to higher outdoor air temperature and the natural ventilation will induce air flow into buildings to increase heat transfer from indoor space and human body ${ }^{5}$.

On the other hand, windows and doors are usually shut after sunset in order to prevent mosquitoes from coming into the rooms and also for safety reasons. There is a need to conduct a study on residential building rise university hostels because it is rarely done. Issues that often arise, and often raised by the hostel residents are feeling less comfortable with the environment of their bedroom because of high indoor air temperature. The problem arises mainly during the night time. To fix this, the indoor air of the hostel bedroom is vented to the surrounding using the help of mechanical ventilator as the use of air conditioner is not preferable.

Corresponding author: shaharin@utp.edu.my 
Therefore, it is necessary to know the thermal condition of the bedroom that use mechanical ventilation system and which is not, in order to determine whether the system can help reducing the indoor temperature rise or not ${ }^{6-8}$. The thermal condition in hostel bedrooms during the night time has to be considered carefully because of the high occupancy at that time on campus. This is because the hostel residents which consisting of pre-graduate, undergraduate and postgraduate students favour a comfortable bedroom for them to rejuvenate after long exhausting daytime activities. The objective of this work was to study the thermal indoor conditions of hostel rooms in a university after sunset and the effectiveness of an innovative portable mechanical ventilation system. The effectiveness of ventilation to help in achieving thermal comfort environment will be measured based on the thermal conditions of bedroom before and after the ventilation is installed and perception by the occupants.

\section{Methodology}

The experimental site located in a hot and humid tropical climate zone and therefore treated according to the ventilation requirement for such an area based on published works by other researchers ${ }^{9-14}$. The mechanical ventilation fan must be capable to discharge the minimum air changes required per hour $(\mathrm{ACH})$ for that particular room. To calculate the value of the $\mathrm{ACH}$, the following Equation (1.0) must be satisfied. The volumetric flow rate or ACH required in a bedroom is depending on the volume of bedroom space and the number of air changes rate for typical bedroom space. The equation is very beneficial in selecting the proper fan for ventilation purposes:

$$
Q=\frac{V N}{60}
$$

where $\mathrm{Q}$ is the volumetric flow rate of air in cubic feet per minute ( $\mathrm{cfm}), \mathrm{V}$ is the volume of space in cubic feet, and $\mathrm{N}$ is the number of air changes rate per hour $(\mathrm{ACH})^{4}$. In order to select the correct ventilation fan for the bedroom, it is important to know how much air required to be moved. Table 1 below shows the suggested number of air changes rate for typical bedroom from various ventilation fan manufacturer around the world.

Table 1. Recommended air changes rate for typical bedroom by various ventilation fan manufacturer

\begin{tabular}{|c|c|c|}
\hline Manufacturer & Air Changes Rate & Room Rate Used \\
\hline A & $2-4$ & 4 \\
\hline B & 5 & 5 \\
\hline C & $2-4$ & 4 \\
\hline
\end{tabular}

\subsection{Equipment}

For the purpose of this experiment, OM - DaqPRO 5300 data logger is used to collect various data of temperature in the bedrooms. The data logger will store temperature data and can be extract using computer through DaqLAB software. A typical data logger of this type can support maximum eight points of thermocouple and therefore suitable for temperature measurement activities in this study, at which six points are used. Each of the bedroom composed of the same dimension which is $4 \mathrm{~m} \times 4 \mathrm{~m} \times 3 \mathrm{~m}$. This makes the volume of the bedroom to be $48 \mathrm{~m}_{3}$ or approximately $1700 \mathrm{ft}$. The number of air discharge is taken as 5 (based on Table 1). Hence, the volumetric flow rate can be determined which is $142 \mathrm{cfm}$. The capability of a ventilation fan used in this project is $90 \mathrm{cfm}$. However, with two identical fans, a total of $180 \mathrm{cfm}$ of volumetric flow rate of air can be discharged. Hence, the air exchanges rate can be achieved, which is more than minimum $142 \mathrm{cfm}$ required from the calculation.

\subsection{Building and bedrooms selection}

In this study, Village 5 Block F (V5F) multi-storey hostel building in UTP has been selected as the location to carry out the temperature measurement experiment. The building composed of 5 floors with a total built area of $1246 \mathrm{~m}$. Each floor comprised of 4 identical houses with 6 bedrooms per house. It is selected because it receives hundred percent of solar intensity and does not blocked by other building surround it. The bedrooms are selected based on the difference of floor which is ground floor, third or middle floor and the top floor, and the windows orientation which facing towards Northeast, Northwest, Southeast and Southwest. A total of nine bedrooms are involved in this study. Fig. 1 shows the floor plan with the indication of the bedrooms selected to be monitored. 


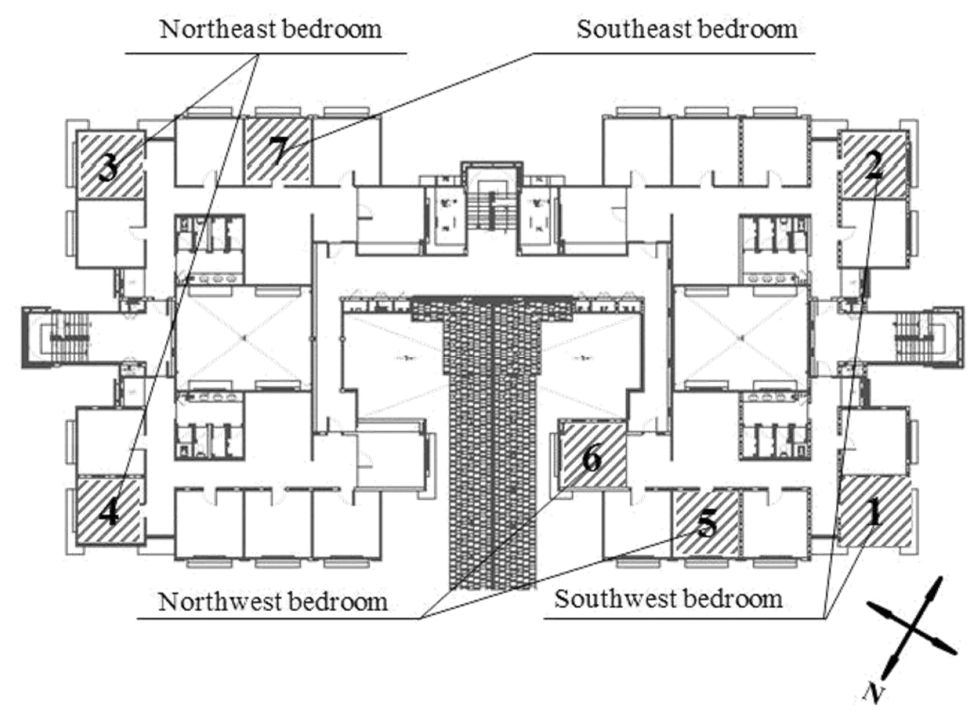

Fig 1. Top floor plan with indication of the monitored bedroom

\section{Experimental setup}

The indoor and outdoor air temperatures of the bedrooms are collected by DaqPRO -portable data logger. The data logger is connected to several thermocouple wire probe which placed inside and outside the bedroom. The data logger is programmed using the computer software DaqLAB. The same programme is used to download the data to a computer. The data were taken every 10 minutes throughout the period of temperature measurement process. A total of six thermocouples type-J wire probes are installed during the measurement where five are installed in various location inside the bedroom and the other is outside. Thermocouple probes for indoor temperature 1,2 and 3 are mounted at approximately $1.5 \mathrm{~m}$ from the floor level except for indoor temperature 4 and indoor temperature 5 which installed at $1.0 \mathrm{~m}$ and $2.0 \mathrm{~m}$ height. Fig. 2 shows the location of thermocouple probes of indoor and outdoor temperatures taken.

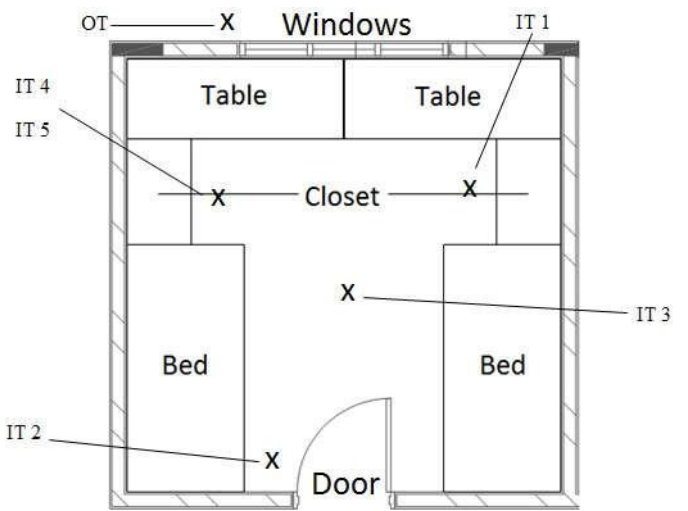

Fig. 2. Indoor and outdoor points of temperatures taken in a bedroom.

The nine bedrooms are monitored during the night time over 12 hours per day from $5 \mathrm{pm}$ to 5 am the next morning. The measurement of the bedroom temperature is taken during sunny days only in order to get an even data collection. During the process, the bedrooms are unoccupied and the windows and the doors are kept closed. The indoor lighting also turned on throughout the period. The bedroom indoor air temperature is measured at various location and height to investigate the existence of air temperature different inside a bedroom. There are three different conditions to take the indoor air temperature measurement in order to study the effect of mechanical ventilation system towards the indoor air temperature with the interest of ceiling fan operation. Table 2 shows the condition for temperature measurement. 
Table 2. Experimental condition of bedrooms for temperature measurement.

\begin{tabular}{|l|l|}
\hline Case & Condition \\
\hline 1 & Only ceiling fan is operating \\
\hline 2 & Only ventilation fans are operating \\
\hline 3 & Both ceiling fan and ventilation fans operate at the same time throughout the experiment \\
\hline
\end{tabular}

\section{Results and discussions}

\subsection{Case 1 (Normal Condition)}

Measurements were conducted in October and November 2012, in which, different condition of bedrooms were applied. Based on the temperature measurements on the top floor bedrooms, it is shown that bedrooms having orientation towards Southwest has the highest indoor temperature while bedrooms having orientation towards Southeast has the least indoor temperature during the night time. Hence, Southwest bedrooms are relatively hot compare to other bedrooms on the same floor. Thus, the same orientation of bedrooms is selected on the first and third floor in order to investigate the different in level of the floor towards the indoor thermal. The same experimental condition is applied to both bedrooms. The indoor temperature of Southwest orientation bedrooms are still high regardless the floor level they are. However, among the three Southwest orientation bedrooms experimented in this study, the bedroom on the top floor has slightly higher indoor temperature compare to the same orientation bedrooms in the other floors. Hence, the Southwest bedroom on the top floor has been selected to be the critical bedroom for further experiments in Case 2 and Case 3 of the experimental conditions. Fig. 3 shows the temperatures for Southwest bedroom on the top floor.
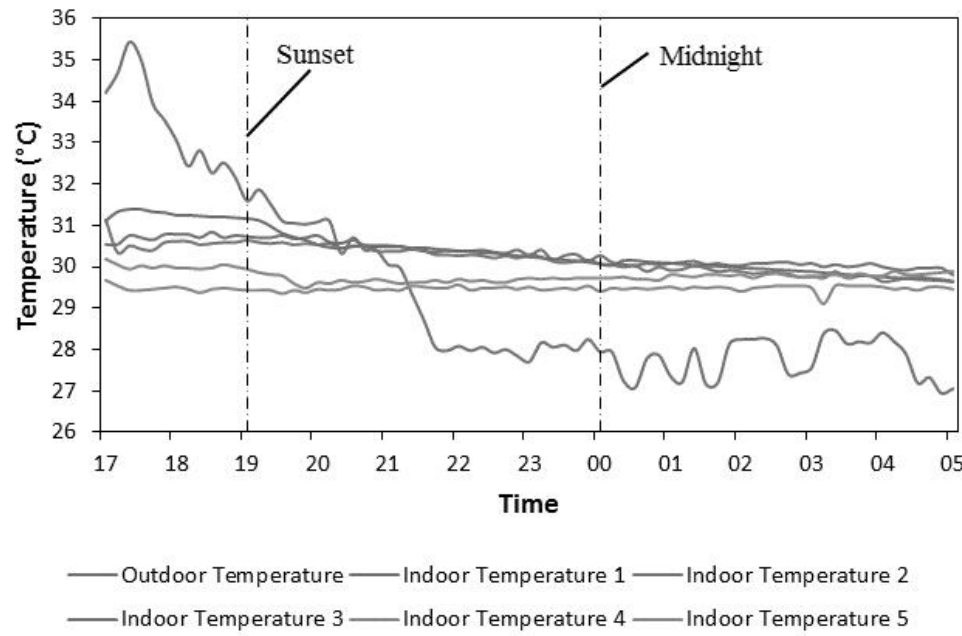

Fig. 3. Hourly variation of indoor and outdoor temperature of top floor Southwest bedroom.

The temperature of the bedroom decreases since the beginning of the experiment approximately at 5 pm up until midnight. Then the temperature maintains and decreases slightly until the end of the experiment at $5 \mathrm{am}$. In this study, thermocouple probes to measure indoor temperature 1,2 and 3 are located at the same height which is $1.5 \mathrm{~m}$ from the floor. However, the Indoor Temperature 1 (IT 1) has the highest temperature between them, followed by Indoor Temperature 3 (IT 3) in the middle of the room and Indoor Temperature 2 (IT 2) placed near the door. This is because the emission of heat stored by the furniture and heat emission from the light effect the IT 1. The IT 3 was less affected by the heat emission from the furniture because it is located away from the furniture and plus it is situated below the ceiling fan. IT 3 experienced the lowest indoor temperature because it is situated far away from the sources of heat emission. Between Indoor Temperature 4 and 5 (IT 4\& IT 5), IT 4 is higher than IT 5 even though it is located nearer to the floor compare to IT 5 . IT 5 should be higher than IT 4 as the fact that hot air rises. However, because of the location of IT 5 that near to the ceiling fan, the wind produced from the fan decreases the temperature and thus make IT 5 lower than IT 4. This is proven in Case 2 when the ceiling fan is not operating; IT 5 is higher than IT 4 as the hot air rises without being pushed back down by the fan. 


\subsection{Case 2}

Fig. 4 shows the result of thermal measurement in top floor Southwest bedroom under the condition of only ventilation fans operating without the operational of the ceiling fan. The windows and door remain closed and the bedroom's light still turned on throughout the experiment.

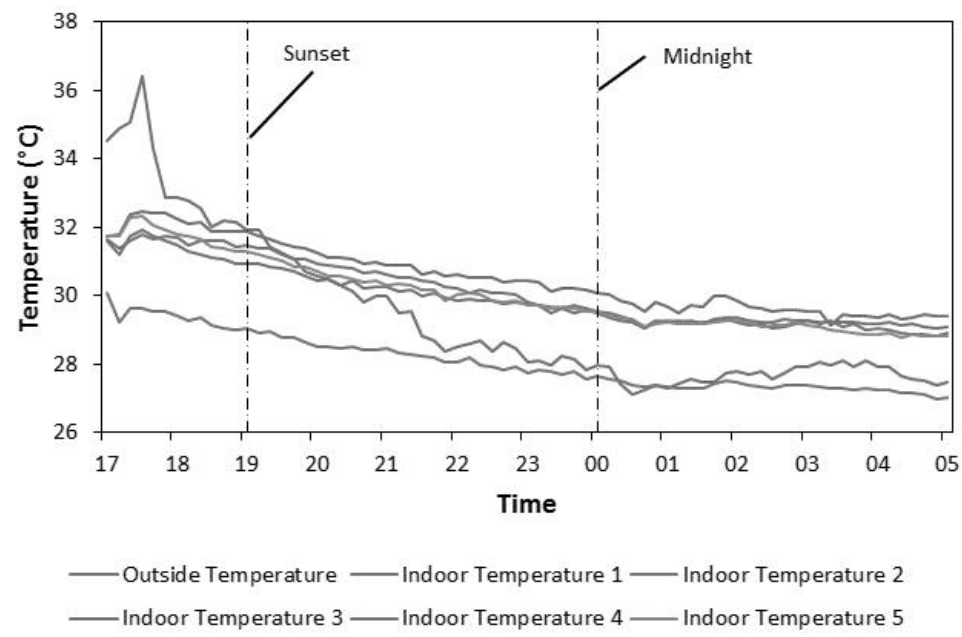

Fig. 4. Hourly variation of indoor and outdoor temperature of top floor Southwest bedroom with only ventilation fans

$$
\text { operating. }
$$

The indoor temperature is dropping faster compare to the indoor temperature in normal condition. This shows that the hot air inside the bedroom is successfully discharged to the surrounding by the ventilation fans during early after sunset time. As night grows, the temperature drop rate becomes slower as heat is dissipated from the furniture and the light to the bedroom space affect the indoor thermal. The average of indoor temperature is still around $30^{\circ} \mathrm{C}$ and above until midnight. During this period, the bedroom is cooler compare to the normal condition (case 1). However, it is still considered warm and near to hot condition as the temperature is still fluctuating around $30^{\circ} \mathrm{C}$ until midnight time. After midnight, the indoor temperature begins to drop at a faster rate for two hours because of large temperature different between the indoor and the outdoor thermal. Then, indoor temperature decreases slowly at almost steady rate until 5 in the morning.

\subsection{Case 3}

In this case, both ventilation fans and ceiling fan were operated at the same time during the course of the temperature measurement period. Other conditions remained the same. Fig. 5 shows the result of the thermal measurement of the bedroom in this kind of condition. The indoor temperature at the beginning of the experiment is lower than indoor temperature in Case 2 with average of $30^{\circ} \mathrm{C}$ despite high outdoor temperature around $33.5^{\circ} \mathrm{C}$. As the time approach to sunset, the indoor temperature drops almost equal to the outdoor temperature. By $10 \mathrm{pm}$, the indoor temperature already beyond $29^{\circ} \mathrm{C}$ and continue to drop even though the outdoor temperature drops at a slow rate. The indoor temperature maintained around $29^{\circ} \mathrm{C}$ until midnight and dropping to $28^{\circ} \mathrm{C}$ at the end of the experiment with the outdoor temperature dropping to minimum $27^{\circ} \mathrm{C}$. This means that the indoor air is circulating and at the same time the hot air is removed from the bedroom even at a slow rate. This helps the bedroom temperature to drop continuously and prevent the thermal condition to become high. 


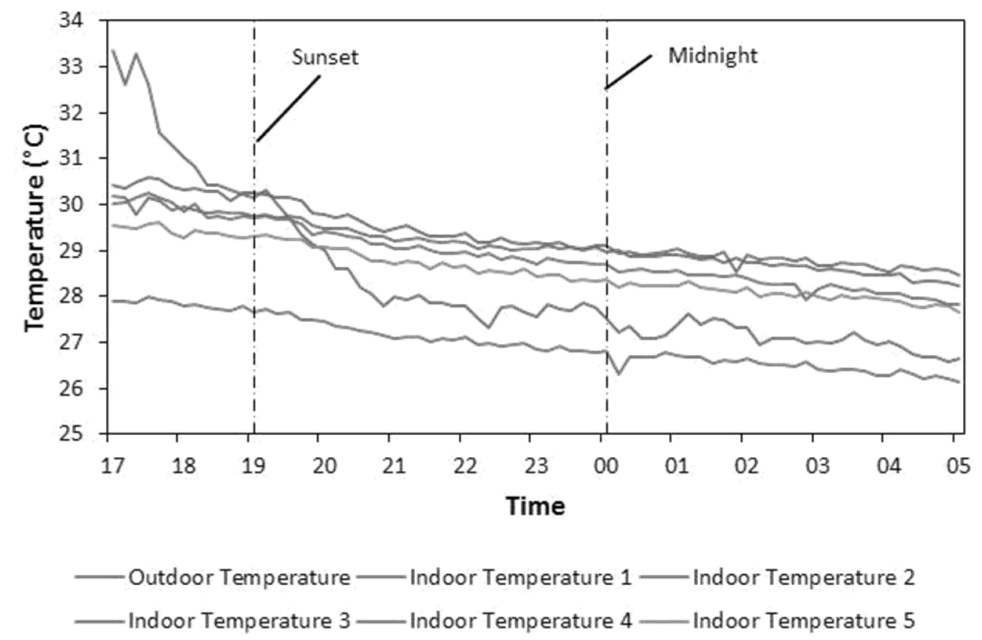

Fig. 5. Hourly variation of indoor and outdoor temperature of top floor Southwest bedroom when both ventilation fans and ceiling fan operating.

\subsection{Temperature difference in critical bedroom}

The temperature difference between the indoor and outdoor thermal of the critical bedroom is determined in all experimental condition to give a better picture on the temperature results. Fig. 6 shows the temperature difference between the indoor and outdoor thermal of the critical bedroom.

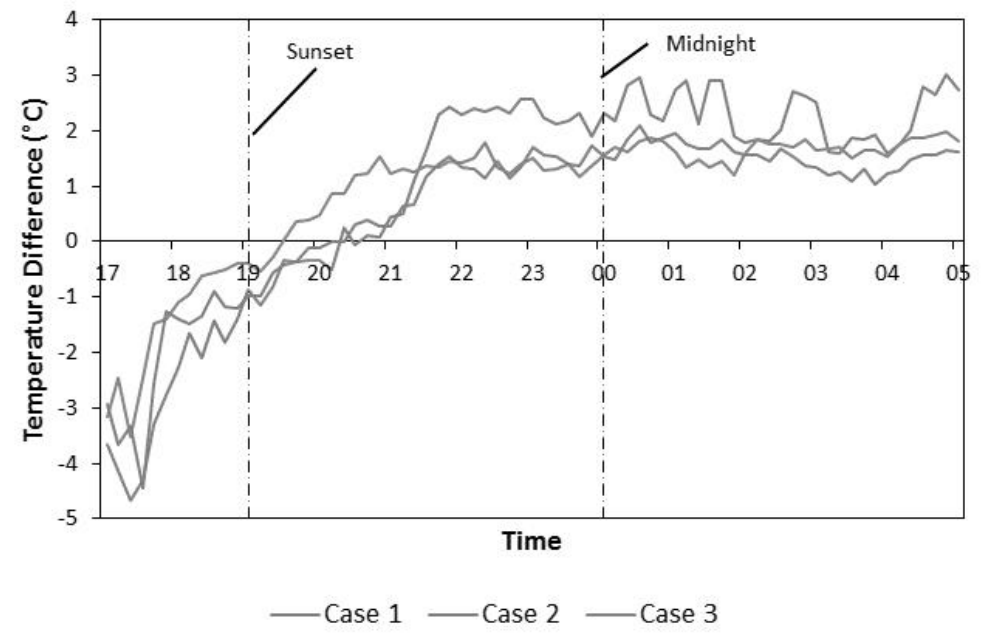

Fig. 6. Temperature difference between the indoor and outdoor thermal of critical bedroom

Negative temperature difference means that the indoor temperature is lower than the outdoor temperature. In this situation, the indoor temperature is selected at Indoor Temperature 1 for comparison because of the occupants tend to spend their night time at this location (table area) to do their homework, surfing the internet, watch movies and other activities in order to get some rest from their tiring days' activities. At the beginning of the experiment until sunset time, the indoor temperature is lower compare to the outdoor temperature. In this case, the temperature difference is highest compare to case 2 and 3 with average of $-2.5^{\circ} \mathrm{C}$, followed by Case 2 and Case 3 . This means that the indoor thermal of Southwest bedroom before sunset is the lowest compare when it is in Case 2 and Case 3. However, after sunset, the temperature different from the indoor and the outdoor rises rapidly at time between 9 to $10 \mathrm{pm}$ which is around $2.5^{\circ} \mathrm{C}$ and kept steady until midnight. The same rising pattern can be observed in Case 2 where only ventilation fan is operating. The only different is the maximum temperature difference before midnight is lower than the normal condition which is $1.5^{\circ} \mathrm{C}$. The same maximum temperature difference occurs in Case 3. However, in Case 3 with both ventilation fans and ceiling fan operating, the temperature starts to differ early, at $7.30 \mathrm{pm}$ and gradually rises and kept at $1.5^{\circ} \mathrm{C}$ of difference starting at $9 \mathrm{pm}$ onwards. This is due to the cloudy weather on the night time when the experiment was carried on compare to the other cases which are the weather is fine during the night time. This situation causes the occupants to 
feel hot at this time during normal condition compare when ventilation fans are operating. After midnight and onwards, same pattern of temperature difference is experienced in all three cases where maximum $0.5^{\circ} \mathrm{C}$ of rises are seen from $12 \mathrm{am}$ to $2 \mathrm{am}$. After that, it drops again $0.5^{\circ} \mathrm{C}$ until 4 am before starts to rise gradually until the end of the experiment.

\section{Conclusion}

From the study, it is found that the bedrooms facing towards the sunset has the highest possibility to become hot during the night time regardless which level of floor the bedrooms are in. However, bedrooms in the top floor are warmer than the bedrooms at a lower level due to fact that hot air rises. Temperature at the table area in the bedroom which the area the occupants spend most of the night time is the highest compare to the temperature under the ceiling fan and near the door. Temperature near the ceiling is higher than the temperature near the floor if there are no cooling sources near it such as the operational of ceiling fan. Otherwise, the temperature near the ceiling would be lower than the temperature near the floor area. In practicing ventilation, the indoor temperature is lower compare with normal condition which ventilation just relies on the ceiling fan operation during the night time. The reduction is about $1.5-2.5^{\circ} \mathrm{C}$. Supporting by the temperature difference between indoor and outdoor, which is $1.0-1.5^{\circ} \mathrm{C}$, the hot indoor thermal condition in a bedroom can be reduced.

Ventilation during the night time is importance especially in a bedroom that facing the sunset because the indoor thermal is high. Using both mechanical ventilation fans and ceiling fan are the best way to reduce the hot indoor condition as the hot air can be discharged from the bedroom and at the same time circulation of air can be promoted in the bedroom by the ceiling fan. Even though the power consumption would be higher when both types of fans are used, the occupants' perception is that it is better than having just ventilation fans to operate in the bedroom because no circulation of air or no movement of air when the ceiling fan is not operating.

\section{References}

1. W.J. Younger, A. Thumann, Handbook of Energy Audits 7th edition (New York: Fairmont Press, Inc. CRC Press, 2007)

2. L.R. Leon, Toxicology, Applied Pharmacology 1(223), pp. 146 (2008)

3. P. Gut, D. Ackerknecht, Climate Responsive Building, pp. 16 (1993).

4. V.I. Soebarto, S. Handjarinto, Proceedings of the Eleventh Symposium on Improving Building Systems in Hot, Humid Climates, pp. 482-491 (Fort Worth, TX, June 1998)

5. ASHRAE Standard 55-1992. 'Thermal Environmental for Human Occupancy' (American Society of Heating, Refrigerating, Air-Conditioning Engineers, Atlanta, 1992)

6. ASHRAE Standard 62.2-2010. 'Ventilation, Acceptable Indoor Air Quality in Low-Rise Residential Buildings', (American Society of Heating Refrigerating, Air-Conditioning Engineers, Atlanta, 2010)

7. D.W. Bearg, 'Indoor Air Quality, HVAC Systems' CRC Press, pp. 64 (1993)

8. H. Feriadi, N.H. Wong, Energy, Buildings 36, pp. 614-626 (2004).

9. T.H. Karyono, Energy, Buildings 23, pp. 161-167 (2003)

10. A.M. Nugroho, Economics, Engineering 2 (1), (2011)

11. F.H. Mallick, Energy, Buildings, pp. 628-637 (2004)

12. Z. Lin, S. Deng, Building, Environment 39, pp.1101-1114 (2004)

13. S.N. Ekasiswi, Architecture \& Environment 6 (1), pp. 60-72, (2007)

14. R. Ruzaimah, H.A. Abdul., Z.A.W Abdul, International Conference on Environment Science, Engineering (ICESE), pp. 167-170 (2011) 